\title{
Barriers, knowledge, and training related to pharmacists' counselling on dietary and herbal supplements: a systematic review of qualitative studies
}

\author{
Jeremy Y. $\mathrm{Ng}^{*} \mathbb{D}^{\mathbb{D}}$, Umair Tahir and Simran Dhaliwal
}

\begin{abstract}
Background: Pharmacists are recognized as one of the most accessible healthcare providers and are licensed to advise patients on drugs and health products including dietary and herbal supplements (DHSs). The objective of this study was to identify barriers, knowledge, and training that pharmacists report related to DHSs counselling.

Methods: MEDLINE, EMBASE, AMED and CINAHL were systematically searched from database inception to May 8th, 2020. Eligible articles contained qualitative data with a specific focus on pharmacists' perceived knowledge, training, and barriers to DHSs counselling. Relevant data were extracted, and a thematic analysis was conducted.

Results: Nineteen articles met the inclusion criteria. The following three main themes were identified: challenges to pharmacists obtaining DHSs education, postgraduate workplace challenges surrounding DHSs, and pharmacists' perceived role and importance on DHSs. Low knowledge of DHSs and the limited regulations surrounding DHSs acting as a barrier to counselling were common findings supported by the eligible articles.

Conclusions: A lack of pharmacists' knowledge and awareness of DHSs stems from a variety of factors including a lack of education and training in the field, limited regulations surrounding DHSs, and inadequate availability of DHS information resources in the pharmacy. Pharmacists were unable to confidently counsel patients due to these aforementioned factors in addition to reporting that they lacked time. Further research that reviews pharmacy education and workplace training, and improving DHS regulations are warranted future directions.
\end{abstract}

Keywords: Dietary supplement, Herbal, Pharmacist, Pharmacy, Qualitative research, Qualitative systematic review

\footnotetext{
*Correspondence: ngjy2@mcmaster.ca

Department of Health Research Methods, Evidence, and Impact, Faculty of Health Sciences, McMaster University, Michael G. DeGroote Centre for Learning and Discovery, Room 2112, 1280 Main Street West, Hamilton, ON L8S 4K1, Canada
}

(c) The Author(s). 2021 Open Access This article is licensed under a Creative Commons Attribution 4.0 International License, which permits use, sharing, adaptation, distribution and reproduction in any medium or format, as long as you give appropriate credit to the original author(s) and the source, provide a link to the Creative Commons licence, and indicate if changes were made. The images or other third party material in this article are included in the article's Creative Commons licence, unless indicated otherwise in a credit line to the material. If material is not included in the article's Creative Commons licence and your intended use is not permitted by statutory regulation or exceeds the permitted use, you will need to obtain permission directly from the copyright holder. To view a copy of this licence, visit http://creativecommons.org/licenses/by/4.0/ The Creative Commons Public Domain Dedication waiver (http://creativecommons.org/publicdomain/zero/1.0/) applies to the data made available in this article, unless otherwise stated in a credit line to the data. 


\section{Background}

The use of dietary and herbal supplements (DHSs) is highly prevalent worldwide. In countries including the United States, United Kingdom, and Denmark, it has been found that $35-60 \%$ of adults use DHSs $[1,2]$. In 2016, the Natural Health Product Survey among Consumers conducted in Canada found that $56 \%$ of respondents had taken DHSs such as vitamins and minerals at least once per week [3]. From the same survey, $56 \%$ of the respondents considered themselves to have poor knowledge about the safety of DHSs [3]. In certain clinic populations, the prevalence of use is even higher; almost all (99\%) patients used DHSs, with $46 \%$ using DHSs concurrently with prescription medications in a large Canadian naturopathic medicine clinic population, however, $42 \%$ of the DHS users had not disclosed this information to their primary care provider [4]. In 1999, a survey conducted in the United States identified that $53 \%$ of DHS users believed that DHSs were completely safe to use and rarely ever caused harm [5]. As DHSs are available without a prescription, consumers may selfmedicate and suffer the potential risks of drug-DHS interactions. According to a study led by the Mayo Clinic in 2002-2003, 34\% of DHS users were at risk of suffering potential herb-drug interactions [5]. A number of studies have identified DHS-drug interactions leading to adverse events $[6,7]$, which is of great concern as many patients often do not consult with their healthcare provider(s) before using DHSs.

The regulatory environment related to DHSs varies across many different countries. Two categories of regulations exist for DHSs: premarket and postmarket regulations [8-10]. Effective premarket regulations require evidence on safety and efficacy to be provided through scientific literature [8]. Additionally, the manufacturing process, quality, and labelling of ingredients must uphold good standards as set by regulatory authorities in each country [8]. Postmarket DHSs regulations usually consist of market surveillance surrounding the products' quality, efficacy, safety, and adverse events as reported by consumers [8]. If a DHS is found to be adulterated, misbranded, or harmful to consumer health, regulatory authorities will take appropriate action and may remove the product from the market [8]. Ideally, DHSs have both premarket and postmarket regulations, as is the case in countries such as Canada [11], while in countries such as the United States, only the latter exists [12]. In countries such as New Zealand, the United Kingdom, Japan, and Australia, only DHSs with therapeutic claims must adhere to both premarket and postmarket regulations, while those with nontherapeutic claims are only assessed through postmarket regulations [13-16].
Regardless of how DHSs are regulated, pharmacists are in a unique position to educate patients about the use, efficacy, side effects, and potential interactions with prescription medications associated with such products. An Australian survey found that $87-92 \%$ of consumers expected pharmacists to be able to provide adequate and reliable information about the safety and efficacy of DHSs [17]. Furthermore, a systematic review identified that pharmacists believe that they have the professional responsibility to counsel patients on the safe use of DHSs [18], and in some jurisdictions, pharmacists are already providing recommendations about DHSs to their patients frequently. A survey found that $40 \%$ of US pharmacists and $28.6 \%$ of UK pharmacists recommended multivitamins more than five times a week [19].

Knowing that pharmacists frequently offer DHSs advice to patients for a wide range of health conditions, it is critical for pharmacists to have a reasonable degree of knowledge about these products. Despite this necessity, multiple surveys have indicated that pharmacists have low knowledge of and confidence in the safety and efficacy of DHSs and drug-DHSs interactions [20, 21]. A preliminary literature search on this topic suggested that a need existed to explore the complexity of pharmacists' experiences with DHSs and assess the context in which findings related to their practice in this area are situated. Therefore, the objective of this review was to identify the barriers, knowledge, and training that pharmacists report related to counselling on DHSs.

\section{Methods \\ Approach}

A qualitative systematic review was conducted to examine pharmacists' knowledge of DHSs using standard methods [22] and Preferred Reporting Items for Systematic Reviews and Meta-Analyses (PRISMA) criteria [23]. A qualitative systematic review seeks to combine findings across multiple studies to understand the complexities of individuals' experiences and perceptions, rather than assessing the effectiveness of an intervention [24, 25]. A protocol was not registered.

\section{Eligibility criteria}

Eligible studies reported qualitative data (e.g. qualitative surveys, interviews, focus groups, and observational studies) on pharmacists' perceptions of their knowledge, training, and barriers related to counselling on DHSs. Mixed-methods studies that contained a qualitative component were also eligible, however, studies that contained solely quantitative data were ineligible. For the purpose of this study, we defined DHSs to include vitamins and minerals, herbal remedies, homeopathic medicines, traditional medicines such as traditional Chinese medicines, probiotics, amino acids, and essential 
fatty acids, which was based on published definitions of DHSs, similar products, or their synonyms [26-29]. Only English-language articles were included, and all studies not meeting the aforementioned eligibility criteria were excluded.

\section{Searching and screening}

MEDLINE, EMBASE, AMED and CINAHL were searched on May 11th, 2020 from inception to May 8th, 2020. JYN designed the search strategy (Table 1) to encompass both keywords and indexed headings related to DHSs, pharmacists, and qualitative research methods. UT and SD independently screened the titles and abstracts recovered from all four databases, independently and in duplicate. Any discrepancies were resolved through discussion between all three authors. The same process was undertaken for the full-text screening of eligible studies.

Table 1 MEDLINE Search Strategy for Studies Reporting Qualitative Data Regarding the Pharmacists' Knowledge of DHSs Executed May 11, 2020

Database: Ovid MEDLINE(R) and Epub Ahead of Print, In-Process \& Other Non-Indexed Citations, Daily and Versions (R) < 1946 to May 08, 2020> Search Strategy:

1 dietary supplement*.mp. (67505)

2 exp. Dietary Supplements/ (75009)

3 natural health product*.mp. (415)

4 natural product*.mp. (37584)

5 vitamin*.mp. (266966)

6 exp. Vitamins/ (320422)

7 mineral*.mp. (190102)

8 exp. Minerals/ (164674)

9 (herb* adj1 (medic* or therap* or supplement*)).mp. (24484)

10 exp. Medicine, East Asian Traditional/ or exp. Medicine, Chinese

Traditional/ or exp. Herbal Medicine/ or exp. Plants, Medicinal/ or exp.

Phytotherapy/ (108689)

11 tcm.mp. (10185)

12 exp. Drugs, Chinese Herbal/ (42957)

13 traditional Chinese medicine.mp. (19492)

14 herbalism.mp. (149)

15 exp. Homeopathy/ (4722)

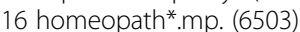

17 probiotic.mp. (16394)

18 exp. Probiotics/ (16825)

19 or/1-18 (961675)

20 (pharmaci* or pharmacy).mp. (88138)

21 exp. Pharmacy Research/ or exp. Education, Pharmacy, Continuing/ or exp. Pharmacy/ or exp. Evidence-Based Pharmacy Practice/ or exp.

Clinical Pharmacy Information Systems/ or exp. Pharmacy Residencies/ or exp. Education, Pharmacy/ or exp. Community Pharmacy Services/ or exp. Education, Pharmacy, Graduate/ or exp. Pharmacy Service, Hospital/ (30644)

22 exp. Pharmacists/ (16527)

23 or/20-22 (88138)

24 (qualitative* or survey* or focus group* or interview* or observational* or descriptive* or mixed method*).mp. (1736863)

2519 and 23 and 24 (602)

26 limit 25 to english language (536)

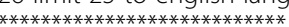

\section{Data extraction}

A data extraction form was created a priori to collect information from each eligible article. The following items were extracted and summarized: title of study; author; year published; country/countries of participants; term(s) used to describe DHS; regulatory status of the DHSs; types of DHSs included in the study; study methodologies; theoretical underpinnings; pharmacist type; number of participants; outcomes; themes discussed; main findings; challenges encountered by the study population; limitations to the study; and study conclusions. UT and SD independently extracted data and discrepancies were resolved through discussion with JYN.

\section{Thematic analysis}

Thematic analysis was conducted based on the data extracted from Table 2 and Table 3, which included the themes, main findings, challenges encountered, limitations and conclusions. The available qualitative data was first summarized in tables and then analyzed by all three authors. UT and SD interpreted the evidence from the included papers to identify common key concepts. JYN, UT, and SD used words and phrases that captured key concepts to create codes, thematically organized codes into groups, and presented a discussion based on the research question as well as highlighted knowledge gaps in the currently published literature. Any disagreements were resolved through discussion.

\section{Results}

Search results

Searches identified a total of 1695 items, of which 1385 were unique, and 1272 titles and abstracts were eliminated, leaving 113 full-text articles for further review. Of those, 94 were deemed ineligible, because they did not include qualitative data $(n=89)$, were conference abstracts $(n=3)$ or were irretrievable $(n=2)$, leaving a total of 19 articles that were included in this qualitative systematic review [30-48]. A PRISMA diagram can be found in Fig. 1.

\section{Characteristics of included studies}

As shown in Table 2, eligible articles were published from 2004 to 2020 and originated from 12 countries. The largest number of studies originated from the United States $(n=4)$. Most studies' pharmacists practiced in a jurisdiction where regulations on DHSs existed but were limited $(n=7)$. Although many terms were used to describe dietary and herbal supplements (DHSs), the most common included natural health products $(n=$ $3)$, dietary supplements $(n=3)$, and complementary and alternative medicine $(n=3)$. The most common research method used across eligible articles was the qualitative interview $(n=28)$. Most studies' participants consisted of 


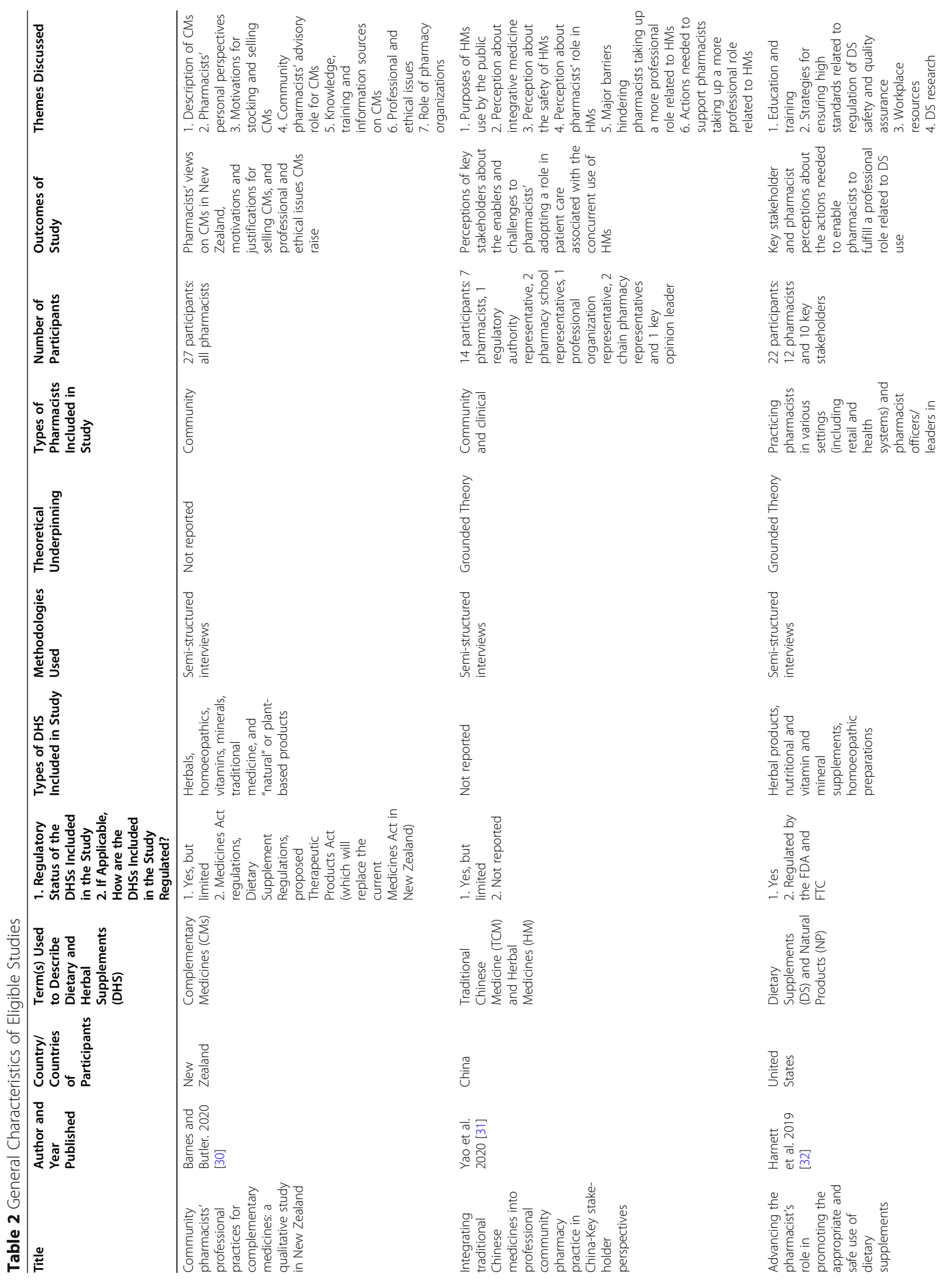




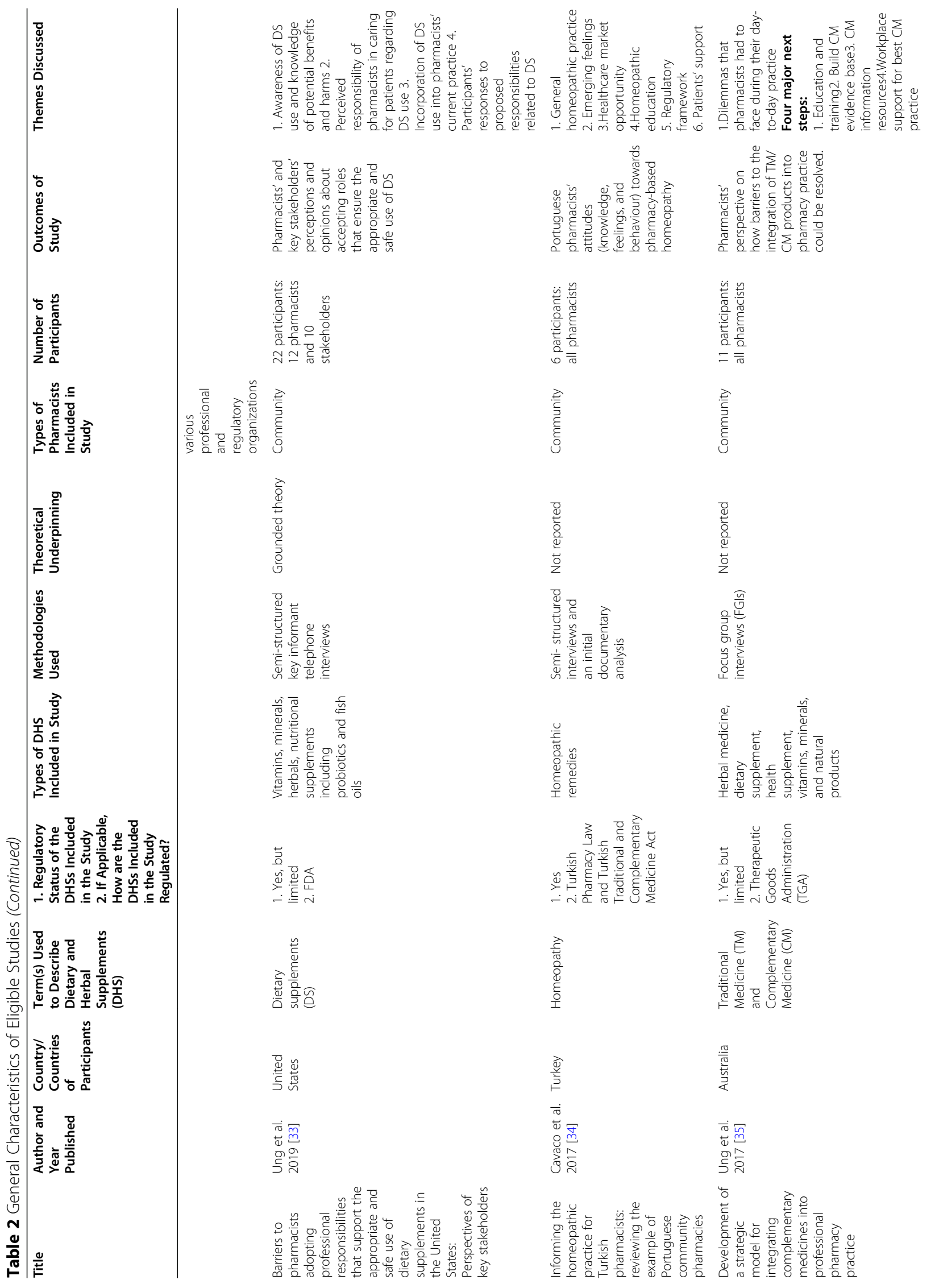




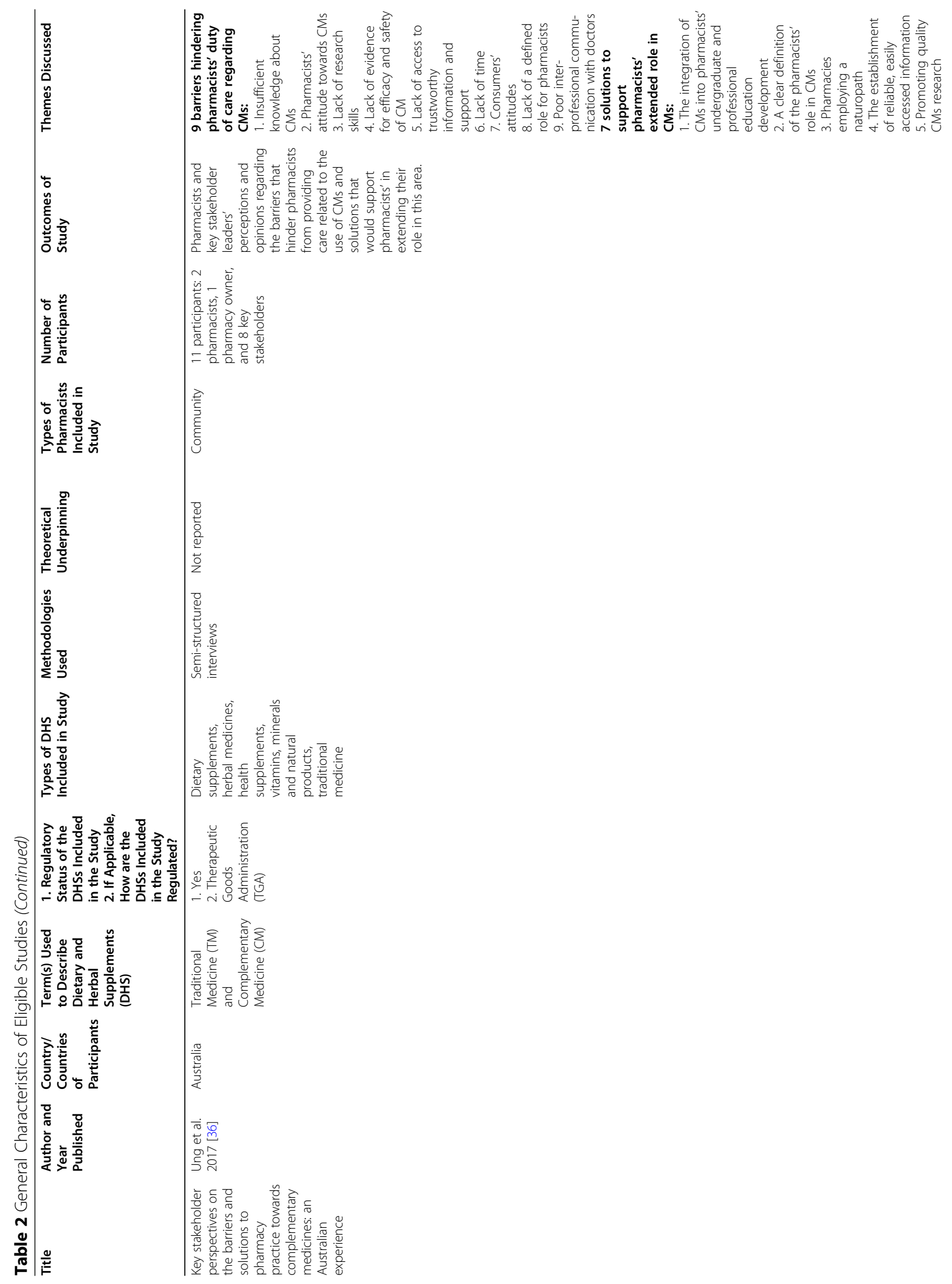




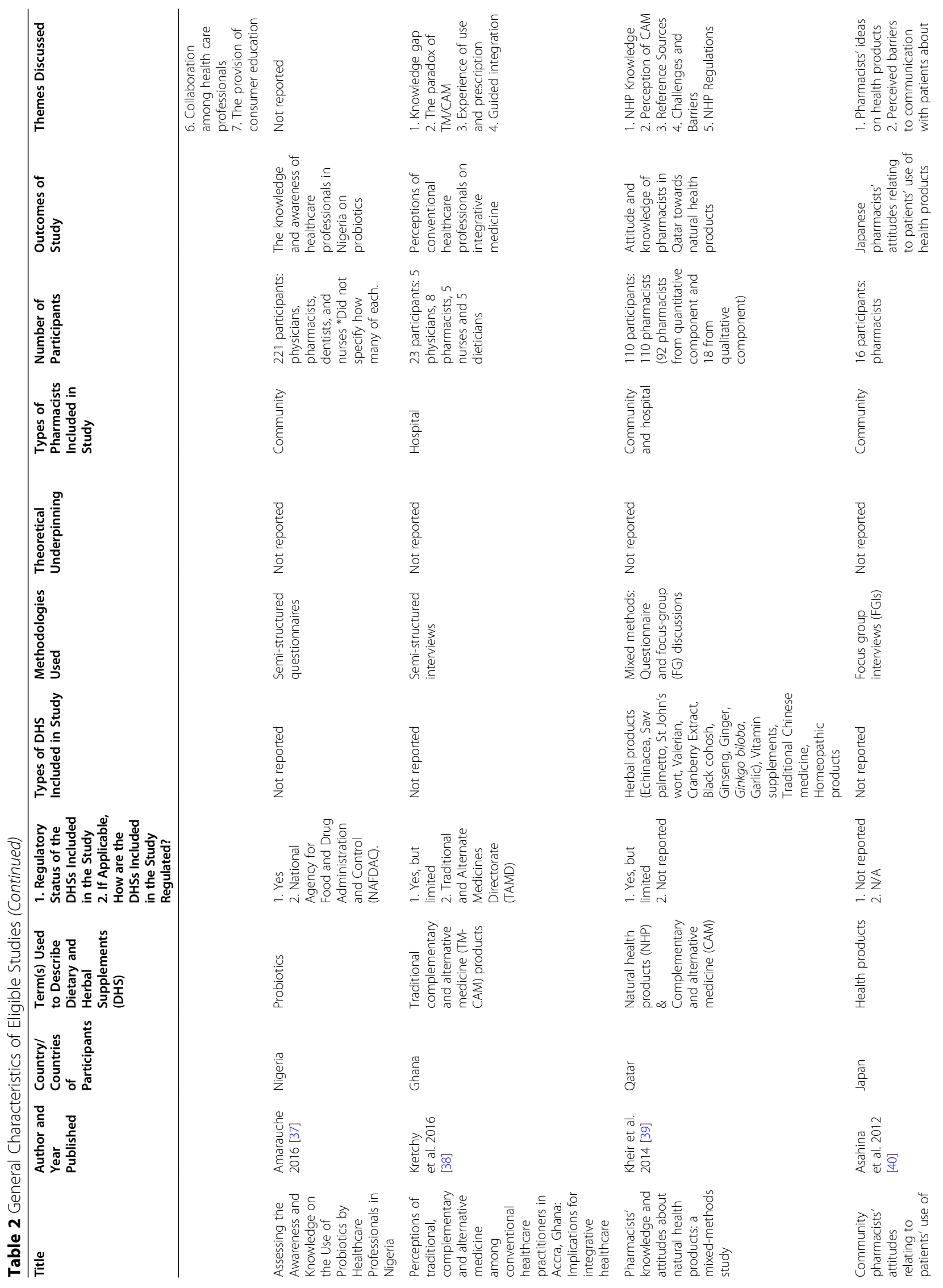




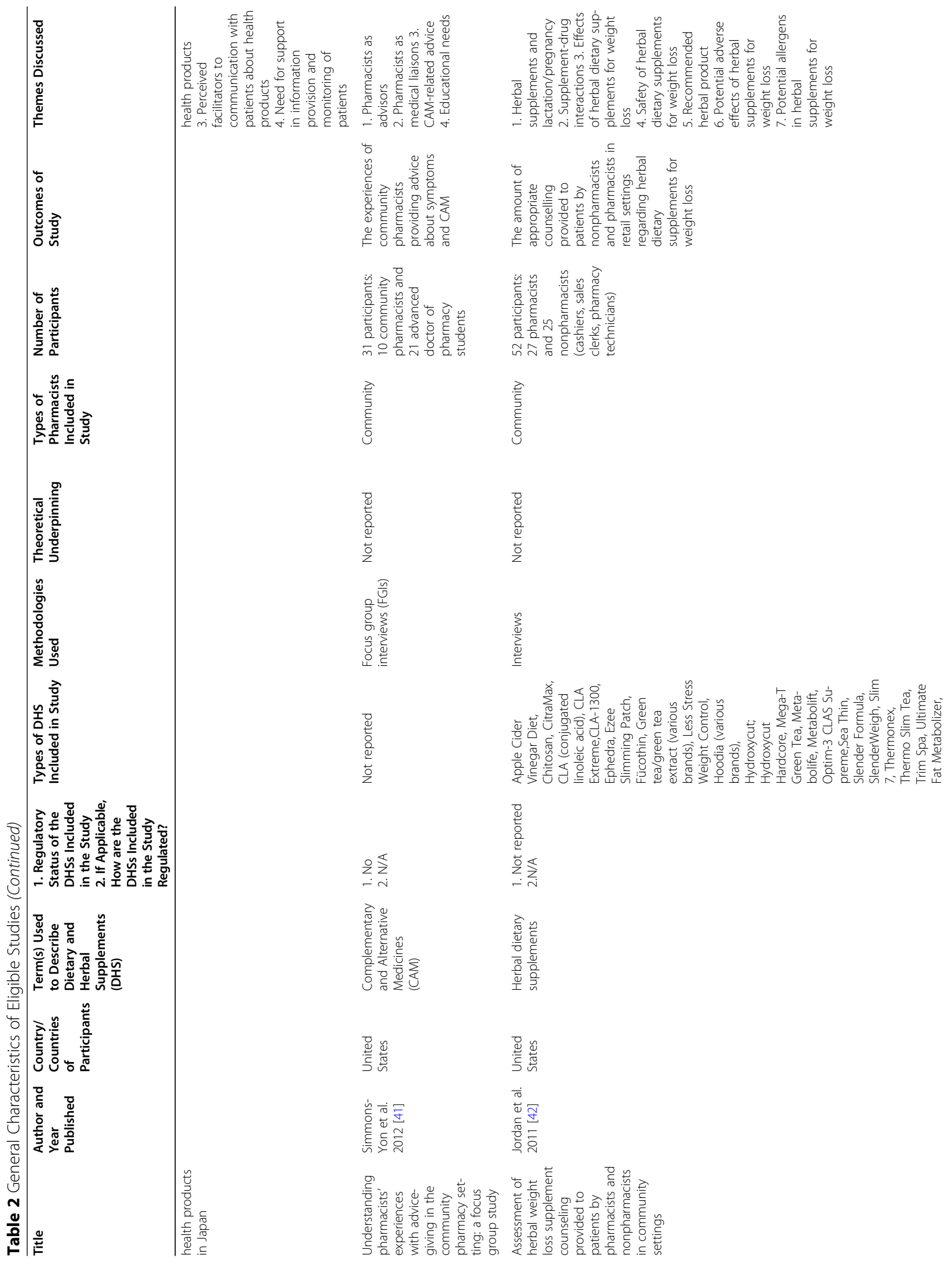




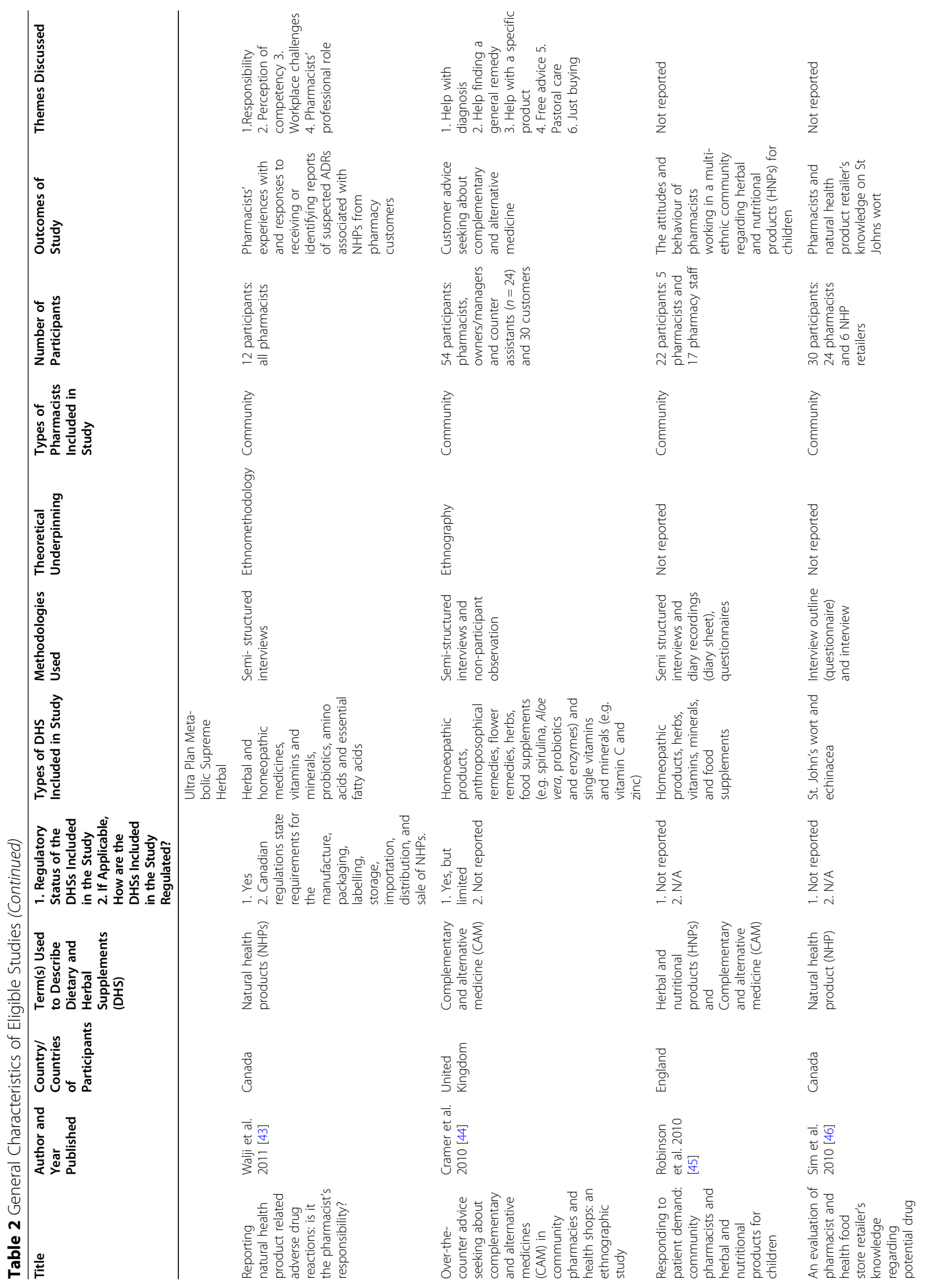




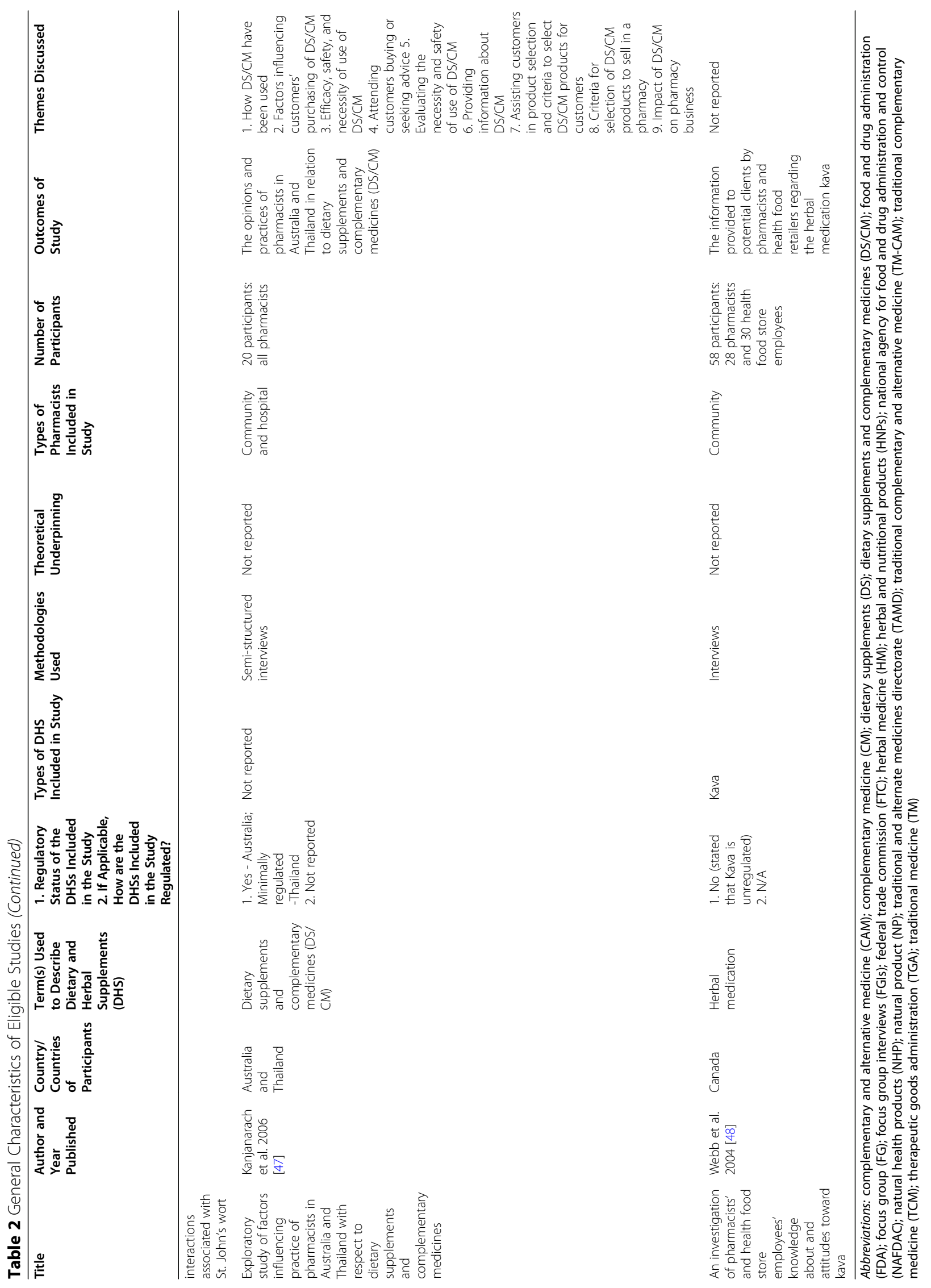


Table 3 Outcomes and Findings of Eligible Studies

\begin{tabular}{|c|c|c|c|c|c|}
\hline Title & $\begin{array}{l}\text { Author and } \\
\text { Year } \\
\text { Published }\end{array}$ & Main Findings & $\begin{array}{l}\text { Challenges Encountered by } \\
\text { Study Population }\end{array}$ & Limitations to the Study & Conclusions \\
\hline $\begin{array}{l}\text { Community pharmacists' } \\
\text { professional practices for } \\
\text { complementary medicines: a } \\
\text { qualitative study in New } \\
\text { Zealand }\end{array}$ & $\begin{array}{l}\text { Barnes and } \\
\text { Butler. } 2020 \\
\text { [30] }\end{array}$ & $\begin{array}{l}\text { 1. Participants found it } \\
\text { difficult to clearly describe } \\
\text { products they considered } \\
\text { complementary medicines. } \\
\text { 2. Perspectives towards CMs } \\
\text { ranged from strongly } \\
\text { supportive to somewhat } \\
\text { sceptical } \\
\text { 3. Consumer demand and } \\
\text { profits were the most stated } \\
\text { motivations for selling CMs. } \\
\text { 4. Pharmacists limited }\end{array}$ & $\begin{array}{l}\text { 1. Lack of knowledge/training } \\
\text { on CMs } \\
\text { 2. Lack of specific regulatory } \\
\text { framework for CMs } \\
\text { 3. Lack of evidence-based } \\
\text { studies }\end{array}$ & $\begin{array}{l}\text { 1. Non-representative, pur- } \\
\text { posive/convenience sam- } \\
\text { ple: pharmacists } \\
\text { supportive of CMs may be } \\
\text { over-represented } \\
\text { 2. Possibility of social } \\
\text { desirability bias }\end{array}$ & $\begin{array}{l}\text { Pharmacists justify selling CMs } \\
\text { despite their lack of } \\
\text { knowledge in these products. } \\
\text { Pharmacists are mindful of } \\
\text { professional and ethical issues } \\
\text { regarding CMs, but their } \\
\text { practice is not guided by the } \\
\text { Pharmacy Council of New } \\
\text { Zealand's Code of Ethics. } \\
\text { There lacks a specific } \\
\text { regulatory framework for CMs } \\
\text { in New Zealand. }\end{array}$ \\
\hline
\end{tabular}

Integrating traditional Chinese medicines into professional community pharmacy practice in ChinaKey stakeholder perspectives
Advancing the pharmacist's role in promoting the appropriate and safe use of dietary supplements
Barriers to pharmacists adopting professional responsibilities that support the appropriate and safe use of dietary supplements in the United States: Perspectives of key stakeholders
Yao et al. 1. Participants agreed that $2020[31]$ pharmacists should play a role in drug safety associated with concurrent use of TCM and western medicine

2. Barriers exist within the government, education, pharmacy, pharmacist, and research sectors.

3. Prominent themes were a lack of clarity in defining the pharmacists' role surrounding HMs and a disconnect between current regulatory standards and education system.

4. The most important enablers identified were the development of policies that support pharmacy practice and practice guidelines, the review of competency

standards, and registration criteria.

Harnett et al. 2019

1. Pharmacists proposed they could develop and promote themselves in DS.

2. Four key areas surrounding DS identified by participants as needing improvement were (1) Education and training; (2) Strategies for ensuring high standards related to DS safety and quality assurance (3) Workplace resources (4) DS Research.

Ung et al. 1. Pharmacists acknowledge 2019 [33] their ethical and professional responsibilities regarding dietary supplements. 2. Due to multiple barriers, most pharmacists are not expecting to assume responsibilities regarding dietary supplements soon.
1. Lack of the competence to provide professional service 2. Lack of knowledge about Chinese medicines or conventional medicines

3. Lack of professional image 4. Lack of motivation or interests in direct patient care

5. Lack of information source

6. Lack of practice guidelines
1. Small sample size only representative of a small number of key stakeholders and certain regions of the country

2. The exclusion of other ethnic minority medicine 3. The perspectives of patients and consumers were not included
Key stakeholders report that there are gaps in pharmacists knowledge in HMs and therefore are unable to provide comprehensive pharmaceutical care. Guiding principles that outline standards for such use would serve as a baseline for professional expectations and as a framework to model pharmacy education.
1. Lack of education and training

2. Lack of regulations

3. Lack of workplace

resources

4. Lack of DS research
1. Small sample size limits extrapolation of the results.
Pharmacists and key stakeholders hold reasonable ideas on how to overcome the challenges facing pharmacy related DS use. Pharmacists believe that quality education and training on DS, as well as improvement of DS regulation on a governmenta and industry level are appropriate next steps.

1. Perceived lack of an evidence base and support to access information 2. Concerns about the regulation of DS 3. Services for DS were not considered by pharmacists to be within their scope of practice 4 . Barriers in being able to include DS in electronic records

5. Many pharmacists did not believe they should accept
1. The qualitative approach found rich information not likely to be gleaned from a quantitative survey, precluding generalizability to a larger group 2. Limited number of interviewee participants precludes extrapolation of the results

3. The interviewees comprised 2 separate groups; however, the
Pharmacists lack in their understanding of their professional roles and responsibilities surrounding dietary supplement awareness and use. Key stakeholders need to be involved to improve the situation. 
Table 3 Outcomes and Findings of Eligible Studies (Continued)

\begin{tabular}{l} 
Title \\
\hline Informing the homeopathic \\
practice for Turkish \\
pharmacists: reviewing the \\
example of Portuguese \\
community pharmacies
\end{tabular}

Development of a strategic model for integrating complementary medicines into professional pharmacy practice
Key stakeholder perspectives on the barriers and solutions to pharmacy practice towards complementary medicines: an Australian experience
Assessing the Awareness an Knowledge on the Use of Probiotics by Healthcare Professionals in Nigeria
Perceptions of traditional, complementary and alternative medicine among conventional healthcare practitioners in Accra, Ghana: Implications for integrative healthcare

Pharmacists' knowledge and Kheir et al. attitudes about natural health 2014 [39] products: a mixed-methods

Kretchy et al. 2016 [38]

\section{Author and Main Findings \\ Published}

Cavaco et al. 1. Pharmacists' attitudes 2017 [34] regarding homeopathy is greatly influenced by their education and relationship 2. Specialized homeopathic education was considered an important factor for success. with homeopathic physicians.

Challenges Encountered by Limitations to the Study Conclusions

Study Population responsibility to report suspected adverse events 6. Ambiguity in expectations; lack of clarity

1. Lack in knowledge of homeopathy and the regulatory framework that surrounds it

2. Lack of reliable information resources
Ung et al. 2017 [35]

Ung et al. 2017 [36]

Amarauche 2016 [36]
1. Pharmacists identified 7 key CMs related dilemmas that they face during their day-today practice.

2. Four developments were proposed that require a collaborative effort: education and training; building the evidence base; developing reliable and accessible information resources; and workplace support for best practice

1. The main barriers identified by many pharmacists were a lack of CMs knowledge,

doubts about the evidencebase, a lack of research skills and access to reliable information

2. Participants proposed the integration of CMs curricula into under-graduate and professional pharmacy education and defining a clearer role for pharmacists' standard of practice.

3. Participants had apposing opinions about the role of naturopaths in pharmacies.

1. Healthcare professionals in Nigeria possess limited probiotic products.

2. Amongst physicians, nurses, pharmacists were the most knowledgeable on probiotics.

1. Participants were worried about the possible negative effects of TM-CAM

2. Participants' knowledge of TM-CAM was low.

3. Participants recognized alternative medicine to be as important as conventional medicine.

1. Most pharmacists had average to poor knowledge about NHPs. pharmacists, dentists and
1. Dilemmas surrounding TM/ CM

2. Lack of education 3. Lack of access to reliable information resources

urban areas.
2. Snowballing and self-
selection of participants

1. An over-representation of pharmacists working in the independent pharmacies and underrepresentation of community pharmacists from 2. Snowballing and selfselection of participants

1. Insufficient knowledge about CMs 2. Pharmacists' attitude towards CMs

3. Lack of research skills 4. Lack of evidence for efficacy and safety of CM

5. Lack of access to trustworthy information and support

6. Lack of time

7. Consumers' attitudes 8. Lack of a defined role for pharmacists

9. Poor inter-professional communication with doctors

1. Lack of knowledge 2. Limited access to information on probiotics

\section{Not reported}

1. The findings are only representative of Australia 2. Small sample size

Many barriers exist preventing pharmacists from properly fulfilling their responsibilities surrounding CMs. Collaboration between stakeholders is required to plan the implementation of this extended role for pharmacists.
1. Pharmacists' lack of confidence in the use of TMCAM products

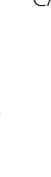

1. Lack of education on NHPs 2. Ethical dilemmas - Large profit margin and financial since a qualitative approach was adopted 2. Participants were based where demand for TMCAM may generally be different from more deprived areas

1. Only Qatar-based pharmacists with contact addresses with the College in more affluent areas,
Pharmacists believe that job satisfaction and appropriate legal frameworks are homeopathic practice. Specialized homeopathic education and improved patient counselling were also considered by pharmacists to be important factors for success. Further investigation the present qualitative findings can be generalized to a larger sample of pharmacists.

This study proposed a strategic model to integrate TM/CM products into pharmacy practice. Pharmacists suggest the need mprovement in education and the regulatory policies related to CMs.
Healthcare professionals in Nigeria have limited awareness and knowledge of the use of probiotics. Seminars and workshops should be hosted to target this issue.

Conventional healthcare professionals welcome the idea of integrative medicine. Practitioners' knowledge on the safety and regulation of TM-CAM must be improved. Pharmacists are disadvantaged in providing adequate services 
Table 3 Outcomes and Findings of Eligible Studies (Continued)

\begin{tabular}{|c|c|c|c|c|c|}
\hline Title & $\begin{array}{l}\text { Author and } \\
\text { Year } \\
\text { Published }\end{array}$ & Main Findings & $\begin{array}{l}\text { Challenges Encountered by } \\
\text { Study Population }\end{array}$ & Limitations to the Study & Conclusions \\
\hline study & & $\begin{array}{l}\text { 2. Poor access to evidence- } \\
\text { based information limited } \\
\text { pharmacists' abilities to } \\
\text { counsel patients. } \\
\text { 3. Pharmacists criticized } \\
\text { undergraduate pharmacy } \\
\text { education for inadequate } \\
\text { preparation to deal with } \\
\text { NHPs. } \\
\text { 4. Pharmacists deem natural } \\
\text { health products to be safe. }\end{array}$ & $\begin{array}{l}\text { bonus associated with the } \\
\text { sale of NHPs presents a sense } \\
\text { of pressure on pharmacists to } \\
\text { sell NHPs }\end{array}$ & $\begin{array}{l}\text { of Pharmacy were con- } \\
\text { tacted, limiting the } \\
\text { generalizability of the } \\
\text { results } \\
2 \text {. Poor response rate }\end{array}$ & $\begin{array}{l}\text { surrounding CAM due to a } \\
\text { lack of knowledge and } \\
\text { limited access to information } \\
\text { resources. A continuing } \\
\text { pharmacy education program } \\
\text { would help pharmacists } \\
\text { improve their NHP related } \\
\text { knowledge. }\end{array}$ \\
\hline $\begin{array}{l}\text { Community pharmacists' } \\
\text { attitudes relating to patients' } \\
\text { use of health products in } \\
\text { Japan }\end{array}$ & $\begin{array}{l}\text { Asahina } \\
\text { et al. } 2012 \\
{[40]}\end{array}$ & $\begin{array}{l}\text { 1. Pharmacists were not } \\
\text { comfortable inquiring about } \\
\text { patients' use of health } \\
\text { products due to the lack of } \\
\text { scientific evidence on safety } \\
\text { and efficacy and feared they } \\
\text { could not advise patients } \\
\text { properly or answer their } \\
\text { questions. } \\
\text { 2. Pharmacists expressed their } \\
\text { concern regarding the } \\
\text { ambiguity surrounding their } \\
\text { professional role as a } \\
\text { pharmacist. } \\
\text { 3. Pharmacists who facilitated } \\
\text { discussions with patients } \\
\text { regarding natural health } \\
\text { products were motivated by } \\
\text { their duties as a pharmacist }\end{array}$ & $\begin{array}{l}\text { 1. Communication between } \\
\text { healthcare professionals on } \\
\text { CAM } \\
\text { 2. Lack of scientific evidence } \\
\text { 3. The ambiguity surrounding } \\
\text { pharmacists' role in relation } \\
\text { to health products }\end{array}$ & $\begin{array}{l}\text { 1. Focus group interviews } \\
\text { cause a lack of } \\
\text { generalizability of the } \\
\text { results } \\
\text { 2. Deficiencies in } \\
\text { heterogeneity within the } \\
\text { focus groups, especially } \\
\text { with respect to sex } \\
\text { distribution } \\
\text { 3. The number of } \\
\text { participants and the } \\
\text { number of FGls were } \\
\text { limited due to the small } \\
\text { number of available } \\
\text { participants } \\
\text { 4. The differences between } \\
\text { users and nonusers of i- } \\
\text { PHISS were not explored } \\
\text { in detail }\end{array}$ & $\begin{array}{l}\text { Ambiguity regarding } \\
\text { pharmacists' professional role } \\
\text { surrounding health products } \\
\text { may cause a lack of } \\
\text { communication with patients. } \\
\text { Pharmacists must realize the } \\
\text { objectives of counselling } \\
\text { patients interested in natural } \\
\text { health products. Further } \\
\text { research is needed to clarify } \\
\text { the roles of pharmacists and } \\
\text { to ensure the implementation } \\
\text { of appropriate educational } \\
\text { objectives in pharmacy } \\
\text { curriculums. }\end{array}$ \\
\hline
\end{tabular}

Understanding pharmacists' experiences with advicegiving in the community pharmacy setting: a focus group study
SimmonsYon et al. 2012 [41] safe.

1. Patients try to delay physician visits by seeking pharmacist advice.

2. Most pharmacists felt uncomfortable

recommending CAM because of the lack of evidence and regulation.

3. To prepare pharmacy graduates for employment in community settings, participants suggested that pharmacy curricula expand training on symptom triage, pharmacist-patient communication, and CAM.

Assessment of herbal weight Jordan et al. loss supplement counseling provided to patients by pharmacists and nonpharmacists in community settings

2011 [42]

1. Pharmacist and nonpharmacist responses to questions regarding product safety differed significantly. 2. Most pharmacists and nonpharmacists advised against the use of herbal products during pregnancy and breast-feeding.

3. When unsure about safety, nonpharmacists did not usually refer the investigators to a health care provider. 4. Pharmacists usually referred the investigator to a health care provider when unsure about safety.

5. Patients may not be given complete or correct

information about herb-drug and herb-disease interactions.

Reporting natural health Walji et al. product related adverse drug 2011 [43] reactions: is it the
1. Pharmacists generally did not submit reports of adverse
events associated with NHPs

\author{
1. Lack of time \\ 2. Complexity of reporting
} process

1. Lack of education

2. Lack of evidence

3. Lack of regulations

1. The perspectives of the

1. Lack of knowledge 2. Lack of time

3. Lack of reliable information 4. Lack of training focus group participants may not be representative of pharmacists and students in other regions 2. Most of the focus group participants were pharmacy students 3. The results are based on self-reported data from the participants

4. Most of the participants worked in chain pharmacies

A lack of education, evidence and regulations on CAM reduces pharmacists' comfort levels in recommending CAM to patients. Pharmacy education should be enhanced to include training on CAM use. Pharmacies should provide easily accessible educational materials for pharmacists on CAM products to better enable them to answer patient inquiries.

1. Exclusion of participants outside of Phoenix, AZ

2. The interview process did not allow for interviewers to obtain a detailed history of each participant's training in herbal products

Counselling on herbal supplements provided by personnel at health food stores, retail stores, grocery stores, and pharmacies was highly variable. The herbal and medical communities should work together to create mechanisms by which patients can be properly informed about herbal products.
Pharmacists' perceptions of their professional roles may explain their reporting 
Table 3 Outcomes and Findings of Eligible Studies (Continued)

\begin{tabular}{|c|c|c|c|c|}
\hline & $\begin{array}{l}\text { Author and } \\
\text { Year }\end{array}$ & Main Findings & $\begin{array}{l}\text { Challenges Encountered by } \\
\text { Study Population }\end{array}$ & \\
\hline
\end{tabular}

pharmacist's responsibility?

Published

Over-the-counter advice seeking about complementary and alternative medicines (CAM) in community pharmacies and health shops: an ethnographic study
Responding to patient demand: community pharmacists and herbal and nutritional products for children
An evaluation of pharmacist and health food store retailer's knowledge regarding potential drug interactions associated with St. John's wort

Exploratory study of factors influencing practice of pharmacists in Australia and Thailand with respect to dietary supplements and complementary medicines

\author{
to the national ADR reporting \\ system due to several barriers. \\ 2. Pharmacists who reported \\ adverse events did so \\ because they saw themselves \\ as 'knowledge generators' \\ 3. There is a need for more \\ formal education and training \\ on NHPs.
}

Cramer et al. 1. Most customers purchasing 2010 [44]

CAM products need extensiv help selecting an appropriate remedy

2. Pharmacists (and counter staff) lack training on CAM products, preventing them from providing appropriate and detailed advice. 3. Health shops may lack knowledge regarding potential interactions between pharmaceutical products and CAM

Robinson et al. 2010 [45]

1. Pharmacists were generally open to herbal and nutritional products and were keen to meet the increasing demand.

2. Pharmacists reported feeling competent to give advice on HNPs.

3. Pharmacists wished to increase their knowledge on HNPs to maintain professionalism, but information on HNPs was limited.

4. Pharmacists understand and empathize with customer demand for HNPs.

Sim et al. 2010 [46]

1. Most pharmacists and NHP retailers recognized that $\mathrm{St}$. John's wort could be usefu for improving mood.

2. Overall low knowledge on potential herb-drug interactions.

Kanjanarach et al. 2006 [47]

1. Australian pharmacists evaluated the safety of DS/ $\mathrm{CM}$ in the same way as for conventional medicines.

2. Thai pharmacists quickly assessed customers' health before selling them DS/CM products.

3. Both Thai and Australian pharmacists provided inadequate information about

DS/CM products and their efficacy.

4. Australian pharmacists recommended products that they were knowledgeable about.

5. Thai pharmacists would suggest brands that yielded a higher profit margin.

6. Neither Australian nor Thai pharmacists were proactive in

3. Lack of knowledge

4. Varying opinions in

pharmacists' responsibilities

and roles in ADR reporting

pharmacists

behaviour for suspected

adverse drug reactions

associated with NHPs.

Information regarding safety and ADRs is lacking in herbal medicines. The improvement of pharmacy education and

clearly defining the professional role of a pharmacist are important next steps.

Customers require help selecting CAM products since there are a wide variety of products offered in pharmacies and health stores. Pharmacists and health product retailers are lacking

in the support needed surrounding CAM. Staff in health food stores and pharmacists would benefit from further training and education.

1. Lack of knowledge

1. Small sample size and specific location; findings from this study may not be generalizable
Pharmacists acknowledge and empathize with custome demand for herbal and nutritional products, but they may require continued professional training.
1. Insufficient education and training on NHPs 2. Lack of quick access to necessary information about herbal medications

Not reported
1. Small sample size included only communitybased pharmacists 2. Incorrect interpretations of responses may have occurred due to the complexity in answers provided by respondents

1. The interviewer was a pharmacist, which could have influenced the way in which respondents answered questions 2. The possible impact of transcription and translation on the meaning of messages
Pharmacists and natura health product retailers must become more educated about potential herb-drug interactions and have access to resources to evaluate potential threats.

Thai nor Australian pharmacists took initiative to provide appropriate services to ensure DS/CM products were being used correctly. Australian and Thai pharmacists had different motives to sell or recommend DS/CM products to customers. Pharmacists professional role in relation to DS/CM products should be clarified 
Table 3 Outcomes and Findings of Eligible Studies (Continued)

\begin{tabular}{|c|c|c|c|c|c|}
\hline Title & $\begin{array}{l}\text { Author and } \\
\text { Year } \\
\text { Published }\end{array}$ & Main Findings & $\begin{array}{l}\text { Challenges Encountered by } \\
\text { Study Population }\end{array}$ & Limitations to the Study & Conclusions \\
\hline & & $\begin{array}{l}\text { providing services to support } \\
\text { the use of DS/CM. }\end{array}$ & & & \\
\hline $\begin{array}{l}\text { An investigation of } \\
\text { pharmacists' and health food } \\
\text { store employees' knowledge } \\
\text { about and attitudes toward } \\
\text { kava }\end{array}$ & $\begin{array}{l}\text { Webb et al. } \\
2004[48]\end{array}$ & $\begin{array}{l}\text { 1. Both pharmacists and } \\
\text { health food store employees } \\
\text { agreed on similar conditions } \\
\text { that could be treated with } \\
\text { kava. } \\
\text { 2. Most pharmacists were } \\
\text { cautious about the safety of } \\
\text { Kava. } \\
\text { 3. Health food employees } \\
\text { were likely to deny the } \\
\text { possibility of adverse effects } \\
\text { associated with kava use. } \\
\text { 4. There was inconsistency in } \\
\text { the level of caution advised } \\
\text { by both groups regarding } \\
\text { safety and efficacy of kava. } \\
\text { 5. Pharmacists and retailers } \\
\text { were greatly misinformed } \\
\text { about kava. }\end{array}$ & Not reported & Not reported & $\begin{array}{l}\text { Pharmacists and health food } \\
\text { store employees have } \\
\text { different views on the safety } \\
\text { of Kava. There is a significant } \\
\text { level of misinformation } \\
\text { provided by health food store } \\
\text { employees about Kava } \\
\text { compared to pharmacists. } \\
\text { Misinformation could lead to } \\
\text { negative health } \\
\text { consequences and a waste of } \\
\text { customers' money. }\end{array}$ \\
\hline
\end{tabular}

Abbreviations: adverse drug reactions (ADRs); complementary and alternative medicine (CAM); complementary medicine (CM); dietary supplements (DS); dietary supplements and complementary medicines (DS/CM); focus group (FG); focus group interviews (FGls); herbal medicine (HM); herbal and nutritional products (HNPs); natural health products (NHP); natural product (NP); traditional complementary and alternative medicine (TM-CAM); traditional complementary medicine (TCM); traditional medicine (TM)

only community pharmacists $(n=15)$. The details associated with all eligible article characteristics can be found in Table 2.

\section{Findings from thematic analysis}

In total, three main themes emerged from our analysis and are described below.

\section{Theme 1: challenges to DHS education}

Many studies found that pharmacists' education fell short of providing them with a thorough understanding of DHSs [30, 31, 33, 34, 37, 39, 41-43]. While some pharmacists expressed that they lacked a DHS education component in their pharmacy curricula [32, 35, 43], those that did receive training stated that they were not confident about their DHS knowledge [42, 43]. Furthermore, the pharmacists suggested that recent graduates may have less knowledge on this topic due to reduced DHS content in the curriculum [42, 43]. Pharmacists described that they were conscious of their poor knowledge and awareness of DHSs, including their safety, efficacy, and drug-DHS interactions [30, 35-38, 43, 46]. Others reported that much of their limited knowledge came from word-of-mouth and the media [38]. This lack of DHSs knowledge decreased pharmacists' willingness to counsel patients on certain products, such as probiotics [37-40, 42, 43, 45]. Many pharmacists agreed with the need for continuing education surrounding DHSs and suggested more DHS curriculum should be incorporated into their university training $[30,32,34,35,37,40$, 45].

Theme 2: post-graduation workplace challenges Sub-theme 2.1: DHS training and resources in the workplace

Following graduation, pharmacists also expressed that DHS training in the workplace was inadequate, which was a factor that added to their lack of DHS knowledge

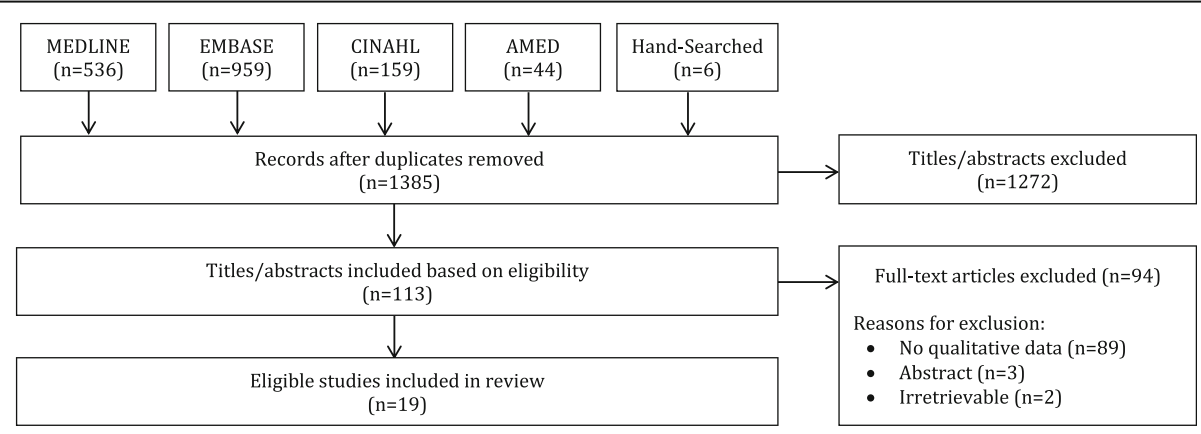

Fig. 1 PRISMA Diagram 
$[36,38,40,44]$. One study noted that many of the pharmacists interviewed had received no formal training on DHSs in the pharmacy and had been introduced to only some herbal medicines [38]. Pharmacists have expressed their desire for increased DHS training in order to gain a comprehensive understanding of these products and to provide better counselling to inquiring patients [31, 38 , 40]. Additionally, the lack of reliable information about DHSs was a key contributing factor to pharmacists' hesitation to counsel patients interested in DHSs [31, 35, 39, 40]. Pharmacists stated that they used evidence-based information to assess the risk-benefits of pharmaceutical medications and similarly require such information for DHSs, particularly with regards to safety and efficacy, in order to effectively counsel their patients [30, 33, 36, 41, 46, 48]. Some also indicated that because of the lack of information, their knowledge about such resources came from media sources, including advertisements [38]. To combat this lack of training, some pharmacists suggested the development of a readily accessible online database for providing information on DHSs [32, 36].

\section{Sub-theme 2.2: lack of time to counsel about DHSs}

Pharmacists voiced that the limited time available for patient counselling surrounding over the counter (OTC) products obstructed proper pharmacist-patient communication $[40,42]$. Due to time constraints, pharmacists were concerned about the extent of the information they could relay, as well as the time they required to investigate the suitability of various DHSs $[33,47]$. As a result of limited time constraints, pharmacists tended to refer patients to alternative healthcare practitioners or answer patient queries briefly, as opposed to providing comprehensive information surrounding these products [42, 47].

\section{Sub-theme 2.3: limited DHSs regulations}

Pharmacists expressed their concerns regarding the limited DHS regulations and framework, which they had identified as a barrier when providing patients with information about such products $[28,30,34,35$, $39,41,47]$. In some countries, there are no requirements regarding whether a pharmacy should or should not sell DHSs [34]. Many pharmacists lacked knowledge about the regulations in their country of practice, which they had identified as a barrier to stocking DHSs in their pharmacy [33, 38]. Moreover, in contrast to traditional OTC pharmaceutical medications, limited regulations surrounding DHSs were a reason why pharmacists lacked the confidence to advise their patients about DHSs [32, 33, 41]. Similarly, these limited regulations lead some pharmacists to believe that these products are unsafe for use, and furthered their reluctance to recommend them to patients [48]. Furthermore, pharmacists suggested that regulations were lacking with respect to their role in dispensing DHSs, and called for regulatory and policy support [31, 39, 47].

\section{Theme 3: perceived role and importance of DHSs Sub-theme 3.1: ambiguity in pharmacists' professional roles} Due to a lack of education and training on DHSs, pharmacists were often unsure of their professional roles and responsibilities surrounding DHSs [33, 36, 40, 43, 47]. Some pharmacists understood that their role should involve providing adequate counselling, accurate information about products safety/efficacy, and recommending DHSs when appropriate [40, 47]. However, pharmacists' lack of structured roles surrounding DHSs has affected their ability to assess the quality of counselling they provide to patients about these products [47]. Structure regarding how pharmacists should approach DHSs in their professional role is largely unknown, which makes it difficult for pharmacists to promote DHSs and advise patients on these products [40, 43, 47]. Pharmacists proposed that additional clarification on their role be provided to ensure a thorough understanding of their responsibilities pertaining to DHSs $[40,43,47]$.

\section{Sub-theme 3.2: perceived importance of DHSs}

Many pharmacists perceived DHSs to be important [32, $38,43,45]$, and some even perceived DHSs to be as important as pharmaceutical medicine and vital to pharmacy practice $[38,43]$. Some pharmacists suggested that their understanding of DHS importance stems from customer interactions, as they had expressed their desire for DHS use [45]. Furthermore, pharmacists have appeared to understand and empathize with customers' demand for DHSs for their children, as they recognized that parents often seek alternative therapies for their children due to their own previous, negative experiences with pharmaceutical medications [45].

\section{Discussion}

A total of 19 studies were deemed eligible and included in this review. An analysis of these studies identified the following themes: challenges to DHS education; postgraduation workplace challenges surrounding DHSs; and pharmacists' perceived role and importance of DHSs. Findings from this review that may assist in improving pharmacists' knowledge about DHSs and the safe usage of DHSs by patients is discussed below.

\section{Comparative literature \\ Challenges to DHS education}

Findings across the literature support that pharmacists' education related to DHSs was limited or non-existent. 
An American cross-sectional survey found that there were notable differences among pharmacy students' recollection of when they had been introduced to DHSs in their program, despite taking the same courses [49]. This highlights the lack of structure surrounding DHSs in pharmacy curricula. This same study identified that the university did not have a course dedicated to DHSs, and suggested incorporating DHSs in didactic teaching [49]. Furthermore, a Jordanian cross-sectional study found that none of the pharmacists surveyed indicated that they had received any guidelines on DHSs during their formal training period before graduation [50].

The lack of DHSs education provided to pharmacists is likely responsible for their poor knowledge of these products, including drug-DHS interactions. An American survey found that only $2.4 \%$ of pharmacists who received inquiries surrounding DHSs felt that they could always answer the questions [51]. Moreover, a cross-sectional survey drew parallels between Saudi Arabian pharmacists and American pharmacists, in which both exhibited a lack of awareness of drug-DHS interactions [52]. Similarly, another American cross-sectional survey found that $26.3 \%$ of pharmacists provided inappropriate advice surrounding drug-DHS interactions [53]. This percentage of inaccurate drug-DHS advice is a reflection of pharmacists' poor understanding of this topic. Notably, this lack of knowledge may be due to the near absence of premarket clinical trials of DHSs. One study found that patients with chronic disease were at the greatest risk of experiencing drug-DHS interactions, and it was suggested that part of this risk was due to the lack of premarketing regulations requiring safety trials on drug-DHS interactions [54]. Our finding suggest that a course dedicated to DHSs in pharmacy education may be of value, as well as improved regulations that mandate premarket clinical data for DHSs to test for drug-DHS interactions. Furthermore, the implementation of mandatory pharmacy practicums may be beneficial, as a Canadian assessment of pharmacy students' knowledge suggested that fourth-year students who had completed a pharmacy practicum performed better on a standardized test about DHSs [55].

\section{Post-graduation workplace challenges}

There have been various calls for improved workplace training to maintain an adequate standard of DHSs knowledge among all pharmacists [18]. A systematic review identified that pharmacists agree that continuing education on DHSs should be mandatory, and noted that topics such as adverse drug reactions (ADRs), patient counselling, therapeutic uses and dosing would be most beneficial to include in this training [18]. Not only is workplace training on DHS limited, but DHSsspecific resources also appear to be lacking. For example, an American cross-sectional survey found that many pharmacists were not satisfied with the resources available to them [47, 56]. Therefore, one of the reasons pharmacists may be unable to counsel patients on the safe use of DHSs, is because they lack the necessary information to do so. Another cross-sectional survey conducted in Saudi Arabia revealed that a major concern for pharmacists included a lack of scientific evidence that supported the use of DHSs [57]. To facilitate pharmacists' acquisition of knowledge, DHS training and continuing education programs should be implemented; furthermore, they should have access to the most up-todate clinical research findings surrounding DHSs.

Compounding this issue is the fact that pharmacists may lack the time to adequately counsel patients about DHSs. This finding is supported by a cross-sectional survey conducted in Saudi Arabia, which found that the most common barrier for pharmacists in providing DHS counselling to patients was a lack of time due to their other responsibilities [57]. Another study that interviewed pharmacists found that very few reported ADRs related to DHSs due to time constraints in the workplace [58]. Since a lack of time is an identified barrier to pharmacists counselling on DHSs or reporting DHSrelated ADRs, the adjustment and re-evaluation of pharmacists' assigned roles warrants further investigation.

The present review also identified that pharmacists were concerned over the limited regulations governing the sale of DHSs, which is another issue also supported by the peer-reviewed literature. A review of issues surrounding complementary and alternative medicine in the United States found that DHSs are not regulated nearly as strictly as pharmaceutical medications, specifically with respect to safety testing, efficacy, and marketing [59]. This is largely because, in the United States, the Food and Drug Administration does not require manufacturers to provide evidence that their DHSs are safe or effective before they are brought to market [18]. Additionally, an Australian survey examining barriers faced by pharmacists in providing complementary and alternative medicine information found that one of the main obstacles included a need for better DHSs regulations [60]. This same study specified that the need for better regulations included more rigorous standards for listing DHSs on the Australian Register of Therapeutic Goods, clearer information about the type of evaluation the DHS was subjected to, and improved labelling of warnings if product effectiveness was not established [60]. Interestingly, a cross-sectional survey found that American pharmacists were less confident in answering patient questions about DHSs when compared to health food store employees [21]. These feelings of hesitation and self-doubt might be attributed to the limited regulations on DHSs, specifically regarding the labelling. In 2015, the New York State attorney general's office found that 
many DHSs sold by major retailers lacked the ingredients listed on the label or contained other substances not listed [61]. As a result, it is not unreasonable to infer that pharmacists working in community settings may have little confidence in the quality of such products. To restore pharmacists' confidence in counselling about DHSs, policymakers, practitioners, and federal health agencies must collaborate to develop improved regulations that govern the sale, safety, and services of these products.

\section{Pharmacists' perceived role and importance of DHSs}

The roles and responsibilities of pharmacists surrounding DHSs, along with standard DHS curricula and workplace knowledge requirements remain unclear across many jurisdictions [62]. This issue should be addressed and defined through clear regulations that define a pharmacist's role and standards of knowledge surrounding DHSs should be included in pharmacy education so that trainees are aware of their future professional responsibilities. Despite the difficulties in acquiring DHS knowledge, pharmacists perceive such products to be important to their profession and their patients. An American study found that pharmacy students considered knowledge of DHSs to be very important [63]. Other studies have found that pharmacists viewed DHSs with importance and recognized the need for further continuing education and professional development opportunities surrounding DHSs [20,40,45].

\section{Future directions for pharmacy education and training on DHSs}

One future direction may include a collaboration between pharmacy associations and academic institutions, in order to encourage the development of guidelines that provide recommendations for DHSs curriculum, continuing education, and clinical practice. Based on the present review's findings, it seems prudent that pharmacy students should be required to complete a course dedicated to the safety, efficacy, and regulations of DHSs within their professional training [49]. The Center for the Advancement of Pharmacy Education (CAPE) is an organization that has identified educational outcomes that should be considered when updating pharmacy curricula. CAPE has called for improved foundational knowledge and encouraged academic institutions to meet their suggested learning objectives in order to guide curricular revision and pharmacy programs [64]. To improve DHS knowledge and education through the re-evaluation and revision of pharmacy curricula, educational outcomes such as those provided by CAPE should be considered. Continuing professional development (CPD) programs such as those offered through the Canadian Pharmacists Association, specifically tailored towards DHSs may be useful in improving pharmacists' knowledge of a variety of relevant topics, such as cannabis [65]. Finally, pharmacy educators need to be aware of the various web-based online resources and their quality, with respect to ADRs, dosing, and the side effects of DHSs, which have been previously summarized [66].

\section{Strengths and limitations}

Common limitations identified by authors of eligible studies Many included studies reported that a small sample size was identified as a limitation [31-33, 36, 40, 43, 45, 46]. The heterogeneity of the participants, with respect to factors such as age, sex, and educational background was also identified as a limitation across some included studies [40-42], as well as the fact that most participants were community pharmacists $[30,33-48]$. The geographic distribution of participants was another limitation; some of the studies were conducted in jurisdictions that may not be representative of all pharmacists' experiences country-wide [31, 38, 42, 43]. To some extent, this review has helped to mitigate this bias, as we combined data from all eligible studies to identify the commonalities between pharmacists working in different regions of the world. Additionally, all but one study incorporated an interview component into their study design [30-48]; reliance on interview data is subject to its own biases which include the researcher misinterpreting participants' responses, or inadvertently influencing the participant to respond in a particular way. For example, if the interviewer is also a pharmacist, this may influence a participant's answer differently than if the interviewer was not a healthcare professional $[46,47]$.

\section{Strengths and limitations of the present systematic review}

One strength of this study included a comprehensive search of the literature across multiple academic databases. Additionally, our systematic review followed PRIS MA guidelines, and screening, data extraction and thematic analysis was conducted in duplicate and reviewed by a third author. One limitation includes the fact that only English language publications were considered for inclusion. Additionally, a small number of articles were irretrievable, despite receiving assistance from our university librarian in placing interlibrary loan requests. Lastly, it should be noted that reviews conducted on topics such as DHSs are limited by the operational definition selected.

\section{Conclusions}

This review provides a summary of the barriers, knowledge, and training that pharmacists report related to counselling about DHSs. Our findings suggest that pharmacists lack general knowledge of DHSs, especially pertaining to drug-DHS interactions. Notably, this 
knowledge gap largely stems from limited pharmacy education and post-graduation training on DHSs, which decreased pharmacists' confidence in providing counselling on DHSs and increased the ambiguity surrounding their professional role. Lack of reliable resources and time were among the most common barriers to counselling about DHSs. High-quality resources that provide safety and efficacy profiles of DHSs should be made easily accessible to pharmacists. Adjustment and reevaluation of pharmacists' assigned roles also warrants further investigation. Furthermore, there is a need to standardize the quantity and quality of DHS curriculum across pharmacy school programs, as well as workplace training and CPD programs surrounding DHSs. It is worthwhile to note that throughout this review, the topic of limited DHS regulations was frequently explored by the included studies and influenced many of the main findings, suggesting the need to further explore how the regulation of these products can be improved. Following the implementation of any of these recommendations, a future qualitative systematic review may serve useful in re-assess pharmacists' experiences with respect to DHSs.

\section{Abbreviations}

ADR: Adverse drug reaction; CAPE: Center for the Advancement of Pharmacy Education; CPD: Continuing professional development; DHS: Dietary and herbal supplement; OTC: Over-the-counter; PRISMA: Preferred Reporting Items for Systematic Reviews and Meta-Analyses

\section{Acknowledgements}

Not applicable.

\section{Authors' contributions}

JYN designed and conceptualized the study, collected and analysed data, critically revised the manuscript, and gave final approval of the version to be published. UT assisted with the collection and analysis of data, co-drafted the manuscript and gave final approval of the version to be published. SD assisted with the collection and analysis of data, co-drafted the manuscript, and gave final approval of the version to be published.

\section{Funding}

JYN was awarded a Research Scholarship and an Entrance Scholarship from the Department of Health Research Methods, Evidence and Impact, Faculty of Health Sciences at McMaster University.

\section{Availability of data and materials}

All relevant data are included in this manuscript.

\section{Declarations}

\section{Ethics approval and consent to participate}

This study involved a systematic review of peer-reviewed literature only; it did not require ethics approval or consent to participate.

\section{Consent for publication}

All authors consent to this manuscript's publication.

\section{Competing interests}

The authors declare that they have no competing interests.
Received: 29 September 2020 Accepted: 10 May 2021

Published online: 25 May 2021

\section{References}

1. Burnett AJ, Livingstone KM, Woods JL, McNaughton SA. Dietary supplement use among Australian adults: findings from the 2011-2012 National Nutrition and physical activity survey. Nutrients. 2017;9(11):1248. https://doi. org/10.3390/nu9111248.

2. Kantor ED, Rehm CD, Du M, White E, Giovannucci EL. Trends in dietary supplement use among US adults from 1999-2012. JAMA. 2016;316(14): 1464-74. https://doi.org/10.1001/jama.2016.14403.

3. Consumer Health Products Survey. TMS Canada; 2016. [cited 2021 Jan 7]. Available from: https://www.chpcanada.ca/wp-system/uploads/2017/12/ Consumer-Health-Product-Survey.pdf.

4. Ng JY, Garber A, Luong M, Cooley K, Busse JW. No improvement in disclosure of natural health product use to primary care medical doctors in the last 15 years: a survey of naturopathic patients. Complement Ther Clin Pract. 2020;39:101106. https://doi.org/10.1016/j.ctcp.2020.101106.

5. Levy I, Attias S, Ben-Arye E, Schiff E. Use and safety of dietary and herbal supplements among hospitalized patients: what have we learned and what can be learned? - a narrative review. Eur J Integr Med. 2017;16:39-45. https://doi.org/10.1016/j.eujim.2017.10.006.

6. Izzo AA, Hoon-Kim S, Radhakrishnan R, Williamson EM. A critical approach to evaluating clinical efficacy, adverse events and drug interactions of herbal remedies. Phytother Res. 2016;30(5):691-700. https://doi.org/10.1002/ptr.5591.

7. Yetley EA. Multivitamin and multimineral dietary supplements: definitions, characterization, bioavailability, and drug interactions. Am J Clin Nutr. 2007; 85(1):269S-76S. https://doi.org/10.1093/ajcn/85.1.269S.

8. Job KM, Kiang TKL, Constance JE, Sherwin CMT, Enioutina EY. Herbal medicines: challenges in the modern world. Part 4. Canada and United States. Expert Rev Clin Pharmacol. 2016;9(12):1597-609. https://doi.org/10.1 080/17512433.2016.1238762.

9. Teng L, Zu Q, Li G, Yu T, Job KM, Yang X, et al. Herbal medicines: challenges in the modern world. Part 3. China and Japan. Expert Rev Clin Pharmacol. 2016;9(9):1225-33. https://doi.org/10.1080/17512433.2016.1195263.

10. Barnes J, McLachlan AJ, Sherwin CM, Enioutina EY. Herbal medicines: challenges in the modern world. Part 1. Australia and New Zealand. Expert Rev Clin Pharmacol. 2016;9(7):905-15. https://doi.org/10.1586/17512433.201 6.1171712 .

11. About Natural Health Product Regulation in Canada. Government of Canada. 2004 [cited 2021 Jan 7]. Available from: https://www.canada.ca/en/ health-canada/services/drugs-health-products/natural-non-prescription/ regulation.html

12. Dietary Supplements. U.S. Food and Drug Administration. FDA; 2020 [cited 2021 Jan 7]. Available from: https://www.fda.gov/food/dietary-supplements

13. Complementary and Alternative Health Care in New Zealand [Internet]. Ministry of Health NZ. [cited 2021 Jan 7]. Available from: https://www. health.govt.nz/publication/complementary-and-alternative-health-care-newzealand-0

14. Food Supplements Regulations. HSIS. [cited 2021 Jan 7]. Available from: https://www.hsis.org/food-supplements-regulations/

15. Tanaka H, Kaneda F, Suguro R, Baba H. Current system for regulation of health foods in Japan. JMAJ. 2004;47(9):436-50.

16. Regulation of complementary medicines in Australia. Therapeutic Goods Administration (TGA). Australian Government Department of Health; 2017 [cited 2021 Jan 7]. Available from: https://www.tga.gov.au/regulationcomplementary-medicines-australia

17. Mehralian G, Yousefi N, Hashemian F, Maleksabet H. Knowledge, attitude and practice of pharmacists regarding dietary supplements: a community pharmacy- based survey in Tehran. Iran J Pharm Res IJPR. 2014;13(4):1457-65.

18. Kwan D, Hirschkorn K, Boon H. U.S. and Canadian pharmacists' attitudes, knowledge, and professional practice behaviors toward dietary supplements: a systematic review. BMC Complement Altern Med. 2006;6:31. https://doi.org/10.1186/1472-6882-6-31.

19. Nelson MV, Bailie G. A survey of pharmacists recommendations for food supplements in the U.s.a. and U.k. J Clin Pharm Ther. 1990;15(2):131-9. https://doi.org/10.1111/j.1365-2710.1990.tb00367.x.

20. Hijazi MA, Shatila H, El-Lakany A, Ela MA, Kharroubi S, Alameddine M, et al. Beliefs, practices and knowledge of community pharmacists regarding 
complementary and alternative medicine: national cross-sectional study in Lebanon. BMJ Open. 2019;9(3):e025074. https://doi.org/10.1136/bmjopen-2 018-025074.

21. Coon SA, Stevens WW, Brown JE, Wolff SE, Wrobel MJ. Comparison of dietary supplement product knowledge and confidence between pharmacists and health food store employees. J Am Pharm Assoc (2003). 2015;55(2):161-8. https://doi.org/10.1331/JAPhA.2015.14071.

22. Cochrane Handbook for Systematic Reviews of Interventions. [cited 2020 Aug 12]. Available from: https://training.cochrane.org/handbook/current

23. Moher D, Liberati A, Tetzlaff J, Altman DG, Group TP. Preferred reporting items for systematic reviews and meta-analyses: the PRISMA statement. PLoS Med. 2009;6(7):e1000097. https://doi.org/10.1371/journal.pmed.1 000097

24. Butler A, Hall H, Copnell B. A guide to writing a qualitative systematic review protocol to enhance evidence-based practice in nursing and health care. Worldviews Evid-Based Nurs. 2016;13(3):241-9. https://doi.org/10.1111/ wvn.12134.

25. Jørgensen CR, Thomsen TG, Ross L, Dietz SM, Therkildsen S, Groenvold M, et al. What facilitates "patient empowerment" in Cancer patients during follow-up: a qualitative systematic review of the literature. Qual Health Res. 2018;28(2):292-304. https://doi.org/10.1177/1049732317721477.

26. Administration AGD of HTG. An overview of the regulation of complementary medicines in Australia. Therapeutic Goods Administration (TGA). Australian Government Department of Health; 2013 [cited 2020 Aug 14]. Available from: https://www.tga.gov.au/overview-regulationcomplementary-medicines-australia

27. Commissioner O of the. FDA 101: Dietary Supplements. FDA. FDA; 2019 [cited 2020 Aug 14]. Available from: https://www.fda.gov/consumers/ consumer-updates/fda-101-dietary-supplements

28. Canada H. Natural health products. aem. 2004 [cited 2020 Aug 14]. Available from: https://www.canada.ca/en/health-canada/services/drugs-healthproducts/natural-non-prescription.html

29. WHO global report on traditional and complementary medicine, 2019. Geneva: World Health Organization; 2019. 226.

30. Barnes J, Butler R. Community pharmacists' professional practices for complementary medicines: a qualitative study in New Zealand. Int J Clin Pharm. 2020;42(4):1109-17. https://doi.org/10.1007/s11096-020-01 093-2.

31. Yao D, Hu H, Harnett JE, Ung COL. Integrating traditional Chinese medicines into professional community pharmacy practice in China - key stakeholder perspectives. Eur J Integrative Med. 2020;34:101063. https://doi.org/10.1016/ j.eujim.2020.101063.

32. Harnett JE, Ung COL, Hu H, Sultani M, Desselle SP. Advancing the pharmacist's role in promoting the appropriate and safe use of dietary supplements. Complementary Therapies Med. 2019;44:174-81. https://doi. org/10.1016/j.ctim.2019.04.018.

33. Ung COL, Harnett JE, Hu H, Desselle SP. Barriers to pharmacists adopting professional responsibilities that support the appropriate and safe use of dietary supplements in the United States: perspectives of key stakeholders. Am J Health Syst Pharm. 2019;76(13):980-90. https:// doi.org/10.1093/ajhp/zxz079.

34. Cavaco AM, Arslan M, Şar S. Informing the homeopathic practice for Turkish pharmacists: reviewing the example of Portuguese community pharmacies. Homeopathy. 2017;106(2):93-102. https://doi.org/10.1016/j. homp.2017.02.003.

35. Ung COL, Harnett J, Hu H. Development of a strategic model for integrating complementary medicines into professional pharmacy practice. Res Soc Adm Pharm. 2017;14(7):663-72. https://doi.org/10.1016/ j.sapharm.2017.07.012

36. Ung COL, Harnett J, Hu H. Key stakeholder perspectives on the barriers and solutions to pharmacy practice towards complementary medicines: an Australian experience. BMC Complement Altern Med. 2017;17(1):394. https:// doi.org/10.1186/s12906-017-1899-5.

37. Amarauche CO. Assessing the awareness and knowledge on the use of probiotics by healthcare professionals in Nigeria. J Young Pharmacists. 2016; 8(1):53-5. https://doi.org/10.5530/jyp.2016.1.12

38. Kretchy IA, Okere HA, Osafo J, Afrane B, Sarkodie J, Debrah P. Perceptions of traditional, complementary and alternative medicine among conventional healthcare practitioners in Accra, Ghana: implications for integrative healthcare. J Integrative Med. 2016 Sep 1;14(5):380-8. https://doi.org/10.101 6/\$2095-4964(16)60273-X.
39. Kheir N, Gad HY, Abu-Yousef SE. Pharmacists' knowledge and attitudes about natural health products: a mixed-methods study. Drug Healthc Patient Saf. 2014;6:7-14. https://doi.org/10.2147/DHPS.S57756.

40. Asahina $Y$, Hori S, Sawada Y. Community pharmacists' attitudes relating to patients' use of health products in Japan. Int J Clin Pharm. 2012;34(4):52937. https://doi.org/10.1007/s11096-012-9640-4.

41. Simmons-Yon A, Roth MT, Vu M, Kavalieratos D, Weinberger M, Rao JK. Understanding pharmacists' experiences with advice-giving in the community pharmacy setting: a focus group study. Patient Educ Couns. 2012;89(3):476-83. https://doi.org/10.1016/j.pec.2012.08.011.

42. Jordan MA, Foster K, Gandhi A, Mohebbi N, Tehrani L. Assessment of herbal weight loss supplement counseling provided to patients by pharmacists and nonpharmacists in community settings. J Am Pharm Assoc. 2011;51(4): 499-509. https://doi.org/10.1331/japha.2011.09233.

43. Walji R, Boon H, Barnes J, Welsh S, Austin Z, Baker GR. Reporting natural health product related adverse drug reactions: is it the pharmacist's responsibility? Int J Pharm Pract. 2011;19(6):383-91. https://doi.org/10.1111/ j.2042-7174.2011.00150.x.

44. Cramer $H$, Shaw A, Wye L, Weiss M. Over-the-counter advice seeking about complementary and alternative medicines (CAM) in community pharmacies and health shops: an ethnographic study. Health Soc Care Community. 2010;18(1):41-50. https://doi.org/10.1111/j.1365-2524.2009. 00877.x.

45. Robinson N, Lorenc A. Responding to patient demand: community pharmacists and herbal and nutritional products for children. Phytother Res. 2010;25(6):892-6. https://doi.org/10.1002/ptr.3357.

46. Sim SN, Levine M. a. H. an evaluation of pharmacist and health food store retailer's knowledge regarding potential drug interactions associated with St. John's wort. Can J Clin Pharmacol. 2010;17(1):e57-63.

47. Kanjanarach T, Krass I, Cumming RG. Exploratory study of factors influencing practice of pharmacists in Australia and Thailand with respect to dietary supplements and complementary medicines. Int J Pharm Pract. 2006;14(2): 123-8. https://doi.org/10.1211/ijpp.14.2.0006.

48. Webb IC, Chatterton JE, Beyerstein BL. An investigation of pharmacists' and health food store employees' knowledge about and attitudes toward kava. Sci Review Alternative Med. 2004;8(2):11-19.

49. Shah B, Siganga W, Mallya U, Shah S. Pharmacy student perspectives on classroom education about herbal supplements. Am J Pharm Educ. 2005: 69(5):102. https://doi.org/10.5688/aj6905102.

50. Shilbayeh SA. Exploring knowledge and attitudes towards counselling about vitamin supplements in Jordanian community pharmacies. Pharm Pract (Granada). 2011;9(4):242-51. https://doi.org/10.4321/s1886-36552011 000400010.

51. Clauson KA, Mcqueen CE, Shields KM, Bryant PJ. Knowledge and attitudes of pharmacists in Missouri regarding natural products. Am J Pharm Educ. 2003; 67(2):41. https://doi.org/10.5688/AJ670241.

52. Alkharfy KM. Community pharmacists' knowledge, attitudes and practices towards herbal remedies in Riyadh, Saudi Arabia. East Mediterr Health J. 2010;16(9):988-93. https://doi.org/10.26719/2010.16.9.988.

53. Sarino LV, Dang KH, Dianat N, Djihanian H, Natanian N, Hudmon KS, et al. Drug interaction between oral contraceptives and St. John's wort: appropriateness of advice received from community pharmacists and health food store clerks. JAPhA. 2007:47(1):42-7. https://doi.org/10.1331/1 544-3191.47.1.42.sarino.

54. Gardiner P, Phillips RS, Shaughnessy AF. Herbal and dietary supplementdrug interactions in patients with chronic illnesses. AFP. 2008;77(1):73-8.

55. Johnson T, Boon H, Jurgens T, Austin Z, Moineddin R, Eccott L, et al. Canadian pharmacy Students' knowledge of herbal medicine. Am J Pharm Educ. 2008;72(4):75. https://doi.org/10.5688/aj720475.

56. Nathan JP, Cicero LA, Koumis T, Rosenberg JM, Feifer S, Maltz F. Availability of and attitudes toward resources on alternative medicine products in the community pharmacy setting. J Am Pharm Assoc. 2005 Nov 1;45(6):734-9. https://doi.org/10.1331/154434505774909715.

57. Al-Arifi MN. Availability and needs of herbal medicinal information resources at community pharmacy, Riyadh region, Saudi Arabia. Saudi Pharma J. 2013; 21(4):351-60. https://doi.org/10.1016/j.jsps.2012.11.004.

58. Green CF, Mottram DR, Raval D, Proudlove C, Randall C. Community pharmacists' attitudes to adverse drug reaction reporting. Int J Pharm Pract. 1999;7(2):92-9. https://doi.org/10.1111/j.2042-7174.1999.tb00955.x.

59. C. Lee $V$. Current issues regarding complementary and alternative medicine (CAM) in the United States. P T 2010;35(9):514-522. 
60. Semple SJ, Hotham E, Rao D, Martin K, Smith CA, Bloustien GF. Community pharmacists in Australia: barriers to information provision on complementary and alternative medicines. Pharm World Sci. 2006;28(6):36673. https://doi.org/10.1007/s1 1096-006-9058-y.

61. O'Connor A. New York Attorney General Targets Supplements at Major Retailers. Well. 2015 [cited 2021 Jan 7]. Available from: https://well.blogs. nytimes.com/2015/02/03/new-york-attorney-general-targets-supplements-atmajor-retailers/

62. Ung $\mathrm{COL}$, Harnett J, Hu H. Community pharmacist's responsibilities with regards to traditional medicine/complementary medicine products: a systematic literature review. Res Social Adm Pharm. 2017;13(4):686-716. https://doi.org/10.1016/j.sapharm.2016.08.001.

63. Axon DR, Vanova J, Edel C, Slack MK. Dietary supplement use, knowledge, and perceptions among student pharmacists. Am J Pharm Educ. 2017;81(5): 92. https://doi.org/10.5688/ajpe81592.

64. Medina MS, Plaza CM, Stowe CD, Robinson ET, DeLander G, Beck DE, et al. Center for the Advancement of pharmacy education 2013 educational outcomes. AJPE. 2013;14(8):77(8). https://doi.org/10.5688/ajpe778162.

65. CPhA - CPD Programs - English. Canadian Pharmacists Association. [cited 2021 Jan 7]. Available from: https://www.pharmacists.ca/education-practiceresources/professional-development/

66. Ng JY, Munford V, Thakar H. Web-based online resources about adverse interactions or side effects associated with complementary and alternative medicine: a systematic review, summarization and quality assessment. BMC Med Informatics Decision Making. 2020;20(1):290. https://doi.org/10.1186/ s12911-020-01298-5.

\section{Publisher's Note}

Springer Nature remains neutral with regard to jurisdictional claims in published maps and institutional affiliations.

Ready to submit your research? Choose BMC and benefit from:

- fast, convenient online submission

- thorough peer review by experienced researchers in your field

- rapid publication on acceptance

- support for research data, including large and complex data types

- gold Open Access which fosters wider collaboration and increased citations

- maximum visibility for your research: over $100 \mathrm{M}$ website views per year

At $\mathrm{BMC}$, research is always in progress.

Learn more biomedcentral.com/submissions 